\title{
Students' Perception of Teaching Behaviour and Its Effect on Evaluation
}

\author{
Bettina Greimel-Fuhrmann \\ Vienna University of Economics and Business
}

\begin{abstract}
This paper explores three different components of teaching behaviour - as it is perceived by the students - and their effect on students' global ratings of their teachers by empirically testing a structural equation model. Potential biases on global ratings like the students' interest in the subject and finding their teacher likeable have also been examined. The model also takes into account that some biases may be a result of teaching behaviour and may not be considered a mere bias of student ratings. The empirical results are based on a quantitative survey of 2,121 students who were asked to evaluate their accounting teachers. While the model shows that global ratings are affected by the students' interest in the subject matter, their attitudes towards evaluating their teachers as well as their teachers' perceived likeability, it also reveals that students' ratings depend mainly on their teachers' behaviour in class, particularly their ability to give clear explanations.
\end{abstract}

\section{Introduction}

Student ratings have been used for many years to evaluate the performance of teachers in their classes [9]. Despite the increasingly widespread use of Students' Evaluations of Teaching (SETs) [10], their validity and usefulness are not undisputed [3, 7]. Although the findings of many research studies underline the validity of SETs, there are almost as many research papers that present data and interpretations suggesting that such ratings are not highly correlated to student learning [7]. Furthermore, it is argued that ratings might be biased by students' interest in the subject, by whether they like their teachers personally, by their grades or their teachers' grading leniency, and other factors [4].

Most previous studies concentrate on just one or a limited number of potential biases [7]. At the same time they neglect factors that should in fact have an influence on ratings, namely the most important components of instructional quality, the teaching behaviour of the instructors being evaluated and their classroom management. In contrast to that approach, the empirical study presented in this paper analyses potential biases in the context of teaching behaviour and classroom management. Additionally, an examination of the effect on ratings of interest and the students' liking for their teacher should also take into consideration that both factors could be a result of good or poor instructional quality. Hence their biasing effect on ratings has to be measured in relation to the extent to which interest and student's liking are affected by the teachers' behaviour in class. Moreover, it seems that very little is known about the students' opinions on evaluating their teachers. But do students themselves consider it useful and appropriate to evaluate their teachers? Their opinion on evaluating their teachers might also have an effect on their ratings. This seems to be a perspective that the abundance of research papers in this field has not concentrated on thus far.

Almost no empirical data is available on the evaluation of teaching at Austrian schools like, for example, at Austrian Commercial Colleges ("Handelsakademien"). In terms of the number of graduates, the Austrian "Handelsakademie" constitutes an increasingly important part of secondary education. The students graduating from a "Handelsakademie" have achieved a level comparable to an undergraduate college. Therefore, the "Handelsakademie" is referred to as a commercial college in the remainder of the text.

The aim of the empirical research presented in this paper is to examine the factors influencing students' global ratings of their teachers at Austrian commercial colleges. As accounting is one of the most important subjects that students are taught for their professional education, the study focuses on accounting teachers, their teaching behaviour as it is perceived by the students and the students' global ratings of their accounting teachers.

\section{Objective}

This paper aims to present and discuss the results of empirical evaluation research on SETs at Austrian commercial colleges. The main objective of this research is to gain comprehensive insight into the students' perspective of instructional quality, i.e. of their perception of distinctive features of teaching behaviour and classroom management [5]. It also examines the students' attitudes towards using 
student ratings for the evaluation of teachers, and possible biases on student ratings. The main research question pertains to the identification of factors that significantly influence the students' global ratings of their accounting teachers at Austrian commercial colleges by combining relevant and irrelevant factors (biases) [5]. Hence the empirical model comprises a quantitative analysis of factors describing teaching behaviour and classroom management as well as potentially biasing factors and their effect on students' global ratings of their accounting teachers.

\section{Research Design}

The first steps of the research project focused primarily on exploring student perceptions of instructional quality and of evaluating their teachers [5]. Forty semi-structured interviews were carried out with students at Austrian commercial colleges. The age of the students interviewed ranges from 15 to 19 , and thus the study includes both younger students as well as those about to graduate. The interviews were analysed by performing a summarising content analysis [8] in order to create categories of the students' lines of reasoning based on their answers to open-ended questions. The results are presented in chapter 4 of this paper.

The main part of the research project comprises a survey based on a questionnaire in order to analyse the factors that influence students' global ratings of their accounting teachers [5]. In addition to the results of the interviews, a number of teaching models were analysed in order to develop teaching behaviour variables for the questionnaire. According to the teaching objectives and contents of the subject accounting, the Direct Instruction model was chosen to serve as a theoretical framework. This model has proved very effective for the systematic acquisition of knowledge [11, 12, 13]. The results of empirical research [1,2] have shown the effectiveness of Direct Instruction in terms of student achievement, a main criterion of effective teaching [3], and of further cognitive and affective learning objectives. On the basis of this model and the interviews, a number of items describing teacher behaviour and classroom management were developed. Ninety teachers (at commercial colleges) were asked to review these items and indicate whether they found the items appropriate for evaluating their teaching. Only a few items had to be removed or reformulated.

Finally, the questionnaire contained nine items to measure the global ratings of teachers by their students which cover overall evaluations like "is a good teacher", "This teacher teaches me a lot in accounting" and "I am satisfied with my teacher", as well as items concerning the stimulation of interest in accounting and of motivation to study accounting. Forty-two items cover different aspects of specific teaching behaviour (like "gives explanations that I can easily understand", "gives concrete examples to explain the subject matter", "is friendly to students" or "gives fair grades") and classroom management. A range of potentially biasing variables completes the questionnaire. The potentially biasing variables are based on the results of the first (qualitative) part of the research project and on additional analyses of factors discussed in previously published research studies $[7,9]$. The questionnaire was carefully tested in a pre-test study with 522 students at commercial colleges and revised several times before it was used in the current study with 2,121 students at commercial colleges from all over Austria.

The relation between the main factors to be examined in this study is summarized in Figure 1.

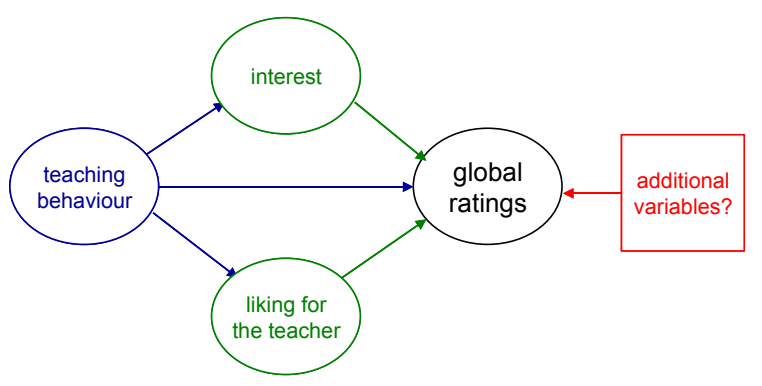

\section{Figure 1. Model of students' evaluations of teaching to be tested}

The model comprises factors that describe teaching behaviour and classroom management (which ought to be relevant for the teachers' global ratings) and factors that should be irrelevant for global ratings [5]. Unlike a number of previous studies, interest in accounting and the students' liking for their teachers are not assumed to be merely a bias of students' global ratings, but are treated as a possible result of good teaching and therefore should have an influence on students' global ratings. The direct and indirect effects involved can be tested statistically by employing structural equation models [5]. In addition, a range of potential biases already discussed in the literature like the students' grades or their teachers' grading leniency as well as some additional biases like the students' opinions on evaluating teachers are introduced into the structural equation model.

\section{Results}

The analysis of the qualitative interview data shows that students characterise good teachers as having some consistently recurring traits: A good teacher gives explanations in an understandable manner, enhances the clarity of explanations by giving practice-oriented, real-life examples, is willing to repeat his/her explanations and to answer students' questions. From a student's point of view, a good teacher would never refuse to explain a matter 
because s/he has already explained it. Furthermore, a good teacher alternates the teaching methods (and media) s/he uses, is interested in and shows understanding for the students' situation and is able to adapt to the students' level. A good teacher is concerned about students' progress in learning and eager to convey new content to them, does not proceed too quickly and is naturally able to maintain student discipline in class. A good teacher's personality is described as humorous, neither too strict nor too lenient, friendly and patient and is considered to be a very fair grader. These results are consistent to research findings of previously published studies on effective teaching [1,2].

Good teachers are described as friendly people who can take a joke without fearing that they could possibly lose control of the class. In fact, good teachers have no "teacher's pets" in class, are respected by students, even if they are not particularly lenient. They are able to command the attention and respect of the entire class without being too strict.

Students also use a few recurrent traits to describe poor teachers. These are, in many cases, the opposites of the traits attributed to good teachers. Basically, monotony seems to be the best description of a poor teacher's lesson from the students' point of view. Many teachers still read aloud from the textbook, telling students to underline what the teacher considers important. They stand in front of the class talking or reading the entire time without even attempting to engage the students in the teaching/learning process. Poor teachers are not able to explain new learning content in a clear, understandable manner. Furthermore, they cannot adapt their teaching and their explanations to the students' level, nor are they willing to repeat an explanation if students have difficulties understanding it. They are also unwilling to answer students' questions, telling them that they should already know the answer or that they can look it up in their textbooks. Two students described a - what they called - "severe" case of a teacher who makes fun of students who ask questions when they do not understand the new learning content.

In the interviews students mentioned a few cases of poor teachers who are so strict and authoritarian that students fear them. In some cases, the students' fear helps teachers to maintain discipline in class. According to the students' descriptions, some of the teachers do not even manage to do so, because the students do not respect the teacher as an authority in the classroom. Poor teachers seem to lack understanding for their students, thus they cannot even take a joke. Therefore, students just learn because of the pressure that is put on them, but they do not really want to, they are not really motivated and have no interest in the subject either.
About one third of the students questions the usefulness and appropriateness of student ratings for the purpose of teacher evaluation. They are not convinced that students' evaluations are just and fair, and they think that students who get bad grades or who do not like the teacher for some reason might also give lower ratings to teachers. Some students think that SETs are not useful because they do not bring about any changes in the teachers' behaviour.

The remaining two thirds of students basically approve of the opportunity to rate their teachers. They think that their ratings might help the teacher improve his/her methods. The interesting question that arises from these results is: Does an approving or disapproving attitude toward teacher evaluations influence the way students actually rate their teachers? Do students who doubt that they are able to give just and fair ratings rate their teachers differently? These questions were addressed in the quantitative part of the research project.

As mentioned in chapter 3 of this paper, the results of the analysis of the interview data were used to develop items of a questionnaire for a quantative survey which was also based on the principles of direct instruction. Exploratory factor analyses were used to examine the factor structure behind the items of the questionnaire covering global ratings, behavioural items, classroom management and selected bias variables (interest, school climate and students' liking for their teachers).

All nine global rating items loaded on one factor, accounting for $69 \%$ of total variance. As to the items describing how students perceive their teachers' behaviours in class, three underlying factors were found that account for $52 \%$ of total variance. Items that loaded on the first factor pertain to the teachers' didactic skills, their "subject-oriented teaching behaviour", like "the teacher gives explanations that I can easily understand", "s/he gives concrete examples to explain the subject matter", "s/he repeats explanations if necessary" and "presentations are logically structured". "Student-oriented teaching behaviour" would be an adequate description of the second factor. Items like "is friendly to students", "is patient with his/her students" or "treats all students the same way", i.e. the teachers' social competences when interacting with the students, load primarily on this factor. The third factor concentrates on classroom management. It covers items like "the teacher is able to maintain discipline in class", "most of the time is dedicated to teaching and learning accounting" and "No student manages to continually disturb my teacher's lessons". All three factors are significantly correlated (at the .01 level, marked by ** in Table 1) with the factor "global ratings" [5]. 


\section{Table 1. Bivariate correlation coefficients of instructional quality with global ratings (**significant at the 0.01 level)}

\begin{tabular}{|l|l|}
\hline $\begin{array}{l}\text { Didactic skills (“subject-oriented teaching } \\
\text { behaviour") }\end{array}$ & $.707^{* *}$ \\
\hline $\begin{array}{l}\text { Socially competent interaction (“student- } \\
\text { oriented teaching behaviour") }\end{array}$ & $.418^{* *}$ \\
\hline Classroom management & $.263^{* *}$ \\
\hline
\end{tabular}

The bivariate correlation coefficients show that there is a particularly strong positive relationship between subject-oriented teaching behaviour and students' global ratings of a teacher (.707). In comparison to clear explanations and well-structured presentations, student-oriented teaching behaviour like the teacher's friendliness, his/her patience with the students, his/her understanding for their situation as well as effective classroom management seem to be relatively less important (.418 and .263). It is due to the large sample size that all three dimensions of instructional quality have highly significant correlations with students' global ratings.

Bivariate correlation coefficients of potentially biasing variables with students' global ratings of their accounting teachers in Table 2 are consistent with findings of previous research [7]: Interest in accounting and grades (as well as expected grades) are positively correlated to SETs (.507 and .261). Very high correlations can be found for the students' liking for their teachers (.687) and their attribution of success in accounting to their teachers (.732) (significant at the .01 level, marked by $* *$ in Table 2).

Positive correlation coefficients can also be found for the students' well-being in school (.195) and classes (.154), the doubt whether students' evaluations are just and fair (.087), and the perception that their accounting teacher would take the ratings seriously (.499). The more the students doubt that SETs are just and fair, and/or the more they think their teachers would take SETs seriously the higher the global ratings of their accounting teachers.
Table 2. Bivariate correlation coefficients of potential biases with global ratings (selected items, ${ }^{* *}$ significant at the 0.01 level)

\begin{tabular}{|l|r|}
\hline $\begin{array}{l}\text { Interest in accounting (one factor } \\
\text { consisting of } 14 \text { variables) }\end{array}$ & $.507 * *$ \\
\hline Grade in accounting & $.217 * *$ \\
\hline Expected grade in accounting & $.261^{* *}$ \\
\hline $\begin{array}{l}\text { Attribution of success in accounting to } \\
\text { the teacher }\end{array}$ & $.732^{* *}$ \\
\hline Class size & $.114 * *$ \\
\hline Effort needed to study accounting & $.432^{* *}$ \\
\hline $\begin{array}{l}\text { Liking the accounting teacher (one factor } \\
\text { consisting of } 4 \text { variables) }\end{array}$ & $.687 * *$ \\
\hline Well-being in class & $.154 * *$ \\
\hline $\begin{array}{l}\text { School climate (one factor consisting of } \\
9 \text { variables) }\end{array}$ & $.195 * *$ \\
\hline It is not easy to teach our class & $.053^{* *}$ \\
\hline Doubt whether SETs are just and fair & $.087 * *$ \\
\hline $\begin{array}{l}\text { The teacher would take students' } \\
\text { evaluations seriously }\end{array}$ & $.499 * *$ \\
\hline $\begin{array}{l}\text { It is more difficult to teach accounting } \\
\text { than to teach other subjects }\end{array}$ & $.198^{* *}$ \\
\hline Fear of failure in accounting \\
\hline $\begin{array}{l}\text { My fellow students' opinion of teachers } \\
\text { is usually correct }\end{array}$ & -.026 \\
\hline
\end{tabular}

However, bivariate correlation coefficients do not account for the simultaneous effect of other factors and biasing variables. Furthermore, it is important to examine not only the direct effect of teaching behaviour on global evaluations, but also the indirect effect via the students' interest in accounting and how they like their teacher.

In order to test the model in Figure 1, a structural equation model has been developed [5]. Based on the exploratory factor analyses described above, seven latent variables are introduced into the model: one factor representing global ratings, three latent variables of teaching behaviour ("subject-oriented" and "student-oriented teaching behaviour" as well as "classroom management"), and latent variables for the interest in accounting, how the students' like their accounting teacher, and school climate. In addition, potential biases were introduced as manifest variables. Figure 2 summarizes the relationship among the factors and contains estimated path coefficients. Almost all path coefficients between latent variables in the diagram are significant (at the .05 level). Statistically insignificant path coefficients are shown in brackets. Based on frequently used fit indices [6], the model fit 
is very satisfying (NFI=.9102, Bentler's Comparative Fit Index $=.9203$, Bollen's Delta2=.9206) [5].

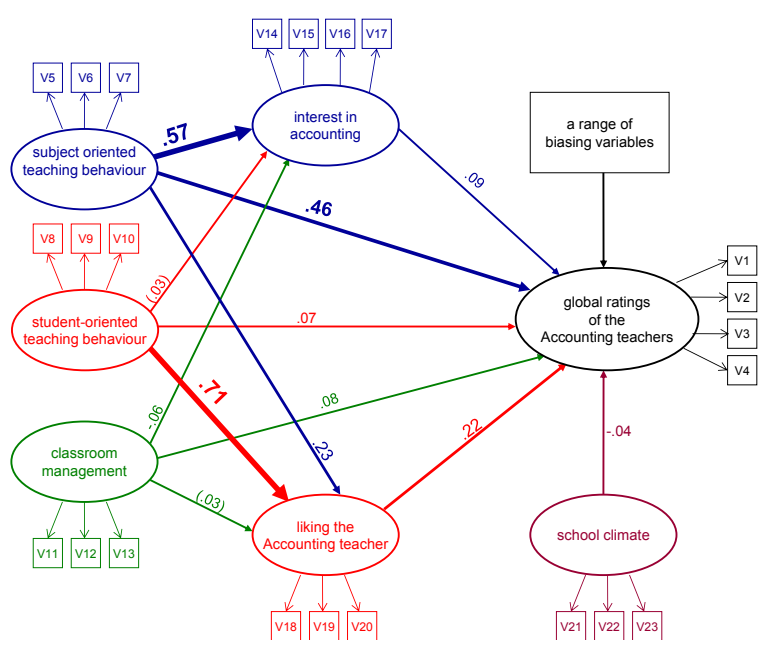

\section{Figure 2. Structural equation model of variables affecting students' global ratings of teachers}

Subject-oriented teaching behaviour has the strongest direct effect on students' global ratings of their accounting teachers (path coefficient $=.47$ ). The direct effects of student-oriented teaching behaviour like being friendly and fair as well as of classroom management are relatively weak ( .07 and .08 , though statistically significant at the .05 level). Interestingly enough, subject-oriented teaching behaviour has an additional indirect effect on global ratings, namely it has a strong effect on students' interest in accounting ( .57) and additionally a moderate effect on students' liking for their teacher. In addition, both factors have a significant effect on global ratings. Therefore, the total effect of subjectoriented teaching behaviour on global ratings equals $.47+.57 \times .09+.23 \times .21=.57$.

There is an additional effect of interest in accounting on global ratings ( .09) that is not accounted for by subject-oriented teaching behaviour or any other variable. Student-oriented teaching behaviour shows a substantial effect on students' liking for their accounting teacher ( .72) which itself has an effect on global ratings. Therefore, the indirect effect of student-oriented teaching behaviour via the variable "liking for the teacher" $(.72 \times .21=$ .15) is much stronger than the direct effect. Again, the students' liking for their teachers has an effect on global ratings that is not accounted for by teaching behaviour ( .21$)$ or by any other variable. This means that even in the context of teacher behaviour, interest in subject matter and the students' perceived likeability of the teacher do have an effect on students' global ratings of the teachers. However, these effects are much smaller than one might have thought considering the bivariate correlation coefficients presented in Tables 1 and 2.

School climate has a very weak effect on global ratings. The same is true for most of the additionally examined biasing variables. The following items have an additional effect (which is statistically significant at the .05 level, due to the large sample size) on global ratings (path coefficients are shown in brackets):

- $\quad$ "a bad mark is attributed to the teacher's (bad) performance in class" (-.087, negative relationship)

- "amount of material covered in class" (.086)

- "a good mark is attributed to the teacher's (good) performance in class" (.082)

- "sex of teacher" (.047, more favourable ratings for female teachers)

- "it is more difficult to teach accounting than other subjects" (.04)

- "it is not easy to teach our class" (.032), "my fellow students' opinion on teachers is usually correct" $(-.024)$

- "students' own doubt whether SETs are just and fair" (.023)

- "fear of failing in accounting" (.023)

Other bias variables that have been frequently tested in previous research such as grades, grading leniency, student's ability, the age of students and teachers, were not found to be significant at the .05 level.

\section{Summary}

The qualitative study that was carried out prior to the main quantitative study shows that the students' evaluations of good and poor teachers correspond closely to the results of many other research projects on instructional quality, most of them also based on empirical data [1,2]. Like the students in our study many researchers have found roughly the same factors to enhance understanding and learning and thus to constitute instructional quality. Clear explanations, a willingness to help students by adapting to their level of knowledge and by answering their questions in a clear, understandable way, and some more creativity in teaching than just reading out of the textbook the entire time are the most important factors in teaching quality from the students' point of view. In addition, the teacher should try to understand the students' positions, show some understanding for their problems without being too lenient, but remain fair. A good laugh should not be forbidden, as long as students respect the teacher and the teacher manages to maintain discipline in class [5]. 
The quantitative analysis has shown that students' global ratings of their accounting teachers mainly depend on the students' perceptions of their teachers' didactic skills, the clarity of their explanations, their ability to use illustrative examples, and the logical structure of their lessons. Not only do these subjectoriented aspects of teaching have the strongest direct effect on students' global ratings but also a strong effect on students' interest in accounting. There is an additional effect of the interest in accounting on global evaluations that cannot be explained by teaching behaviour and that classifies interest in the subject as a bias on global ratings. The studentoriented teaching behaviour only has a relatively weak direct effect on global ratings, but a strong effect on students' liking for their teacher. After all, the effect is not as important as it may seem from bivariate correlation between interest and global ratings. Interestingly enough, subject-oriented teaching behaviour also has an effect on the students' liking for their accounting teacher, although this factor is more affected by the teacher's studentoriented teaching behaviour. There is an additional effect of the students' liking for their accounting teacher that is not accounted for by teaching behaviour. Like their interest in accounting, the students' liking for their teacher may also be regarded as a bias [5].

The effects of most of the additionally examined potential biases are not statistically significant (at the .05 level). Even when they are statistically significant, like some of the students' attitudes towards teachers and teacher evaluation, the effect is relatively small, for example, respondents who doubt that students are able to evaluate their teachers in a just and fair way give more favourable global ratings. The more students think their fellow students' opinion on teachers is usually right, the less favourable their global ratings are. But both path coefficients are less than .03 and therefore considerably less important than subject-oriented and student-oriented teacher behaviour, interest and the students' liking for their teacher.

\section{Discussion}

Basically the results of this study underline the usefulness of students' evaluations of teaching. Although student ratings are not completely unaffected by possible biases like the students' perceived likeability of the teachers, they mainly reflect the students' perceptions of their teachers' (subject-oriented) behaviour in class. Important conclusions for teachers are that the global ratings of their students are mainly determined by their students' perception of their didactic skills, particularly by their ability to explain the subject matter clearly and to use examples to help students understand accounting. Clear explanations, concrete examples and feedback on the students' learning progress contribute more to the students' overall impression of their teachers' performance and to their satisfaction than friendliness, patience and classroom management. Though these elements of instructional quality are vital to teaching effectively [13], they are not sufficient to ensure students' satisfaction with the teaching process. Didactic skills, mainly clarity of explanations and illustrative examples are the key to excellent teaching from the students' point of view. Consequently, teachers could use their students' evaluation as diagnostic feedback on how well they manage to convey and to explain new learning content from the students' point of view.

\section{References}

[1] J. Brophy, Teaching. Educational Practices Series-1, International Academy of Education \& International Bureau of Education, Brussels, 2001

[2] J. Brophy, T. Good, "Teacher Behavior and Student Achievement", in: M. Wittrock, (ed.), Handbook of Research on Teaching, Macmillan Publishing Company, New York, 1986, pp. 328-375

[3] P. Cohen, "Student Ratings of Instruction and Student Achievement: A Meta-analysis of Multisection Validity Studies", Review of Educational Research (Fall 1981), pp. 281-309

[4] A. Greenwald, "Validity Concerns and Usefulness of Student Ratings of Instruction", American Psychologist (November 1997), pp. 1182-1186

[5] B. Greimel-Fuhrmann, A. Geyer, "Die Wirkung von Interesse und Sympathie auf die Gesamtbeurteilung in der Lehrevaluation - Direkte und indirekte Effekte unter Berücksichtigung des Lehrverhaltens", Empirische Pädagogik, vol. 19 (2), 2005, pp.103-120

[6] L. Hatcher, A Step-by-Step Approach to Using the SAS System for Factor Analysis and Structural Equation Modeling. Cary, NC SAS Institute Inc., 1994

[7] H. Marsh, 'Students' Evaluations of University Teaching: Research Findings, Methodological Issues, and Directions for Future Research", International Journal of Educational Research (November 1987), pp. 253-387

[8] P. Mayring, Einführung in die qualitative Sozialforschung. Eine Anleitung zu qualitativem Denken. Beltz Psychologie VerlagsUnion, Weinheim, 1996

[6] H. Rindermann, Lehrevaluation. Einführung und Überblick zu Forschung und Praxis der Lehrveranstaltungsevaluation an Hochschulen mit einem Beitrag zur Evaluation computerbasierten Unterrichts. Verlag Empirische Pädagogik, Landau, 2001 
[10] J. Stronge (ed.), Evaluating Teaching. A Guide to Current Teaching and Best Practice, Corwin Press, Thousand Oaks, California, 1997

[11] F.E. Weinert, „Für und wider die "neuen Lerntheorien" als Grundlagen pädagogischpsychologischer Forschung", Zeitschrift für Pädagogische Psychologie, Vol. 10 (1), Verlag Hans Huber, Bern, pp. 1 - 12, 1996a

[12] F.E. Weinert, „Lerntheorien und Instruktionsmodelle“, in: F.E. Weinert (ed.), Psychologie des Lernens und der Instruktion, Vol. 2 Enzyklopädie der Psychologie, Hogrefe Verlag für Psychologie, Göttingen, pp. $1-48,1996 b$

[13] F.E. Weinert, „Guter Unterricht ist ein Unterricht, in dem mehr gelernt als gelehrt wird“, in: J. Freund, H. Gruber, W. Weidinger, W. (eds.), Guter Unterricht - Was ist das? Aspekte von Unterrichtsqualität, ÖBV Pädagogischer Verlag, Vienna, 1998, pp. 7 - 18 